CLINICAL STUDY

\title{
Effect of smoking on the serum levels of 25-hydroxyvitamin D depends on the assay employed
}

Guri Grimnes $^{1,2}$, Bjørg Almaas ${ }^{3,4}$, Anne Elise Eggen ${ }^{5}$, Nina Emaus ${ }^{5}$, Yngve Figenschau ${ }^{6,7}$, Laila Arnesdatter Hopstock ${ }^{5}$, Moira Strand Hutchinson ${ }^{2}$, Paal Methlie ${ }^{3,4}$, Albena Mihailova ${ }^{8}$, Monica Sneve $^{9}$, Peter Torjesen ${ }^{10}$, Tom Wilsgaard ${ }^{5}$ and Rolf Jorde Ter $^{1,2}$

${ }^{1}$ Medical Clinic, University Hospital of North Norway, N-9038 Tromsø, Norway. ${ }^{2}$ Department of Clinical Medicine, University of Tromso, N-9037 Tromsø, Norway, ${ }^{3}$ Hormone Laboratory, Haukeland University Hospital, N-5021 Bergen, Norway, ${ }^{4}$ Institute of Medicine, University of Bergen, N-5007 Bergen, Norway, Departments of ${ }^{5}$ Community Medicine and ${ }^{6}$ Medical Biology, University of Tromsø, N-9037 Tromsø, Norway, ${ }^{7}$ Department of Medical Biochemistry, University Hospital of North Norway, N-9038 Tromsø, Norway, ${ }^{8}$ Department of Clinical Chemistry, Akershus University Hospital, N-1478 Lorenskog, Norway, ${ }^{9}$ Divison of Ophthalmology, Department of Neurosurgery and Ophthalmology, University Hospital of North Norway, N-9038 Tromsø, Norway and ${ }^{10}$ Hormone Laboratory, Department of Endocrinology, Oslo University Hospital, N-0514 Oslo, Norway

(Correspondence should be addressed to G Grimnes at Medical Clinic, University Hospital of North Norway; Email: guri.grimnes@unn.no)

\begin{abstract}
Objective: Because we found higher serum 25-hydroxyvitamin D (25(OH)D) levels among smokers than among non-smokers with analyses using an electrochemiluminescence immunoassay (ECLIA) from Roche, the purpose of the present study was to examine whether this difference between smokers and non-smokers was maintained using other serum 25(OH)D assays.

Design: A cross-sectional population-based study on 6932 participants from the Tromsø study, 1994-1995, and one validation study comparing six different serum 25(OH)D assays in 53 non-smokers and 54 smokers were performed.

Methods: The association between smoking, season and serum 25(OH)D as measured by ECLIA (Roche) was assessed in the population-based study using general linear models with multivariate adjustments. In the validation study, serum levels of $25(\mathrm{OH}) \mathrm{D}$ were analysed with liquid chromatography coupled with mass spectrometry assay from two different laboratories, RIA (DiaSorin), HPLC, RIA (IDS) and ECLIA (Roche). T-tests and linear mixed model analyses were performed to compare the serum $25(\mathrm{OH}) \mathrm{D}$ levels in smokers and non-smokers within and between the methods.

Results: In the population-based study, the serum levels of $25(\mathrm{OH}) \mathrm{D}$ using the ECLIA method were $51.9,53.2$ and $72.0 \mathrm{nmol} / \mathrm{l}$ in never, former and current smokers $(P<0.01)$. In the validation study, the serum concentration of $25(\mathrm{OH}) \mathrm{D}$ was $10.3 \mathrm{nmol} / \mathrm{l}$ higher in smokers than in non-smokers $(P<0.01)$ using the ECLIA (Roche), while non-significantly lower serum levels of $25(\mathrm{OH}) \mathrm{D}$ were found in smokers using the other five methods.

Conclusions: These two studies indicate that the ECLIA (Roche) overestimates serum 25(OH)D levels in smokers by unknown mechanisms. If confirmed, this might have clinical consequences, and the issue needs further exploration.
\end{abstract}

European Journal of Endocrinology 163 339-348

\section{Introduction}

Current research on vitamin $\mathrm{D}$ is extensive, as illustrated by a PubMed search using the term 'vitamin D' revealing nearly 10000 articles that were published during the last 5 years. Growing evidence relates low serum levels of 25-hydroxyvitamin D (25(OH)D) to a worsening state of a number of diseases. Thus, valid methods for $25(\mathrm{OH}) \mathrm{D}$ measurements are of great importance in both research and clinical practice.

The circulating level of $25(\mathrm{OH}) \mathrm{D}$ is normally used as the marker of an individual's vitamin D status. This reflects the amount of vitamin D produced in the skin during ultraviolet $\mathrm{B}$ (UVB) exposure (cholecalciferol $\left.\left(25(\mathrm{OH}) \mathrm{D}_{3}\right)\right)$ and the amount of vitamin D ingested from food (ergocalciferol $\left(25(\mathrm{OH}) \mathrm{D}_{2}\right)$ or $\left.25(\mathrm{OH}) \mathrm{D}_{3}\right)$. Food sources of vitamin D include fatty fish, cod liver oil and fortified food such as dairy products in addition to supplements. In Norway, cholecalciferol is almost exclusively used as fortification and supplementation. A number of different methods are used to determine serum levels of $25(\mathrm{OH}) \mathrm{D}$, including RIAs or competitive protein binding assays, and direct physical detection methods such as HPLC and liquid chromatography coupled with mass spectrometry (LC-MS/MS). These methods differ in several aspects, as described in a recent review by Hollis (1), and also discussed by Carter (2).

Results regarding the vitamin D status in smokers are conflicting. Several studies report lower serum 25(OH)D levels in smokers (3-10), while others find no 
significant differences in serum 25(OH)D levels between smokers and non-smokers (11-21). In the Tromsø study, 1994-1995 (called the Tromsø study in the text that follows), where a relatively new electrochemiluminescence immunoassay (ECLIA) from Roche (called ECLIA (Roche) in the text that follows) was used, smokers had significantly higher serum 25(OH)D levels than non-smokers. As this finding was unexpected, we hypothesised the presence of interfering substance(s) in smokers causing bias in the ECLIA (Roche) 25(OH)D method. Consequently, we performed a validation study comparing the ECLIA (Roche) assay with five other methods of $25(\mathrm{OH}) \mathrm{D}$ measurement in serum samples from 54 smokers and 53 non-smokers. In this report, we present the results obtained from the Tromsø study and the validation study.

\section{Subjects and methods}

\section{The Tromso study}

Study population The Tromsø study is a repeated population-based study conducted in the municipality of Tromsø, Norway, situated at $69^{\circ} \mathrm{N}$ (current population 67 000). The study was initiated in 1974, focusing originally on cardiovascular diseases. However, the study has evolved through the years with increasing emphasis on other conditions and chronic diseases, for example osteoporosis, diabetes, chronic obstructive pulmonary disease, cancer and dementia. The Tromsø study has been performed six times at regular intervals by inviting the inhabitants of the municipality of Tromsø. The latest health survey was conducted in 2007-2008.

In 1994, all individuals aged 25 years or older were invited to participate in the fourth survey of the Troms $\varnothing$ study. A total number of 27158 persons participated in the first visit, providing an attendance rate of $77 \%$ among eligible inhabitants. All men aged 55-74 years, all women aged $50-74$ years and a sample of $5-10 \%$ of the remaining age groups between 25 and 84 years were invited to undergo a more extensive clinical examination (second visit), and 7965 persons, or $78 \%$ of those invited, attended (22). The study was conducted by the University of Tromsø in cooperation with the National Health Screening Service, and was approved by the Regional Committee of Research Ethics and the Norwegian Data Inspectorate. Each participant gave written informed consent prior to the examinations.

Measurements The participants filled in self-administrated questionnaires on socio-demographic factors, medical history, lifestyle factors, and dietary habits including vitamin D supplementation. All participants attended a physical examination where the questionnaire was checked for incomplete answers, and blood samples were taken. We defined vitamin D supplementation as use of cod liver oil (yes/no) and/or multivitamins containing vitamin D (yes/no).
Physical activity level was calculated by adding together hours of moderate and hard physical activity during leisure time per week. To identify current, former and never smokers, we used a combination of the following questions: 'Do you smoke cigarettes daily?' (yes/no); for previous or current smokers: 'How many cigarettes do you, or did you smoke daily?' (hand rolled + factory made), and 'If you currently smoke, or have smoked before, how many years in all have you smoked daily?'. We also used the smoking variable 'If you previously smoked daily, how long is it since you stopped (years)?'. Subjects answering yes to 'Do you smoke a pipe daily?' $(n=52)$ or 'Do you smoke cigars/cigarillos daily?' $(n=43)$ were coded as current smokers. Owing to inconsistent answers in the questionnaires, 100 participants were excluded from the analyses since their smoking status could not be classified with certainty. Height and weight were measured wearing light clothing and no shoes, and body mass index (BMI) was defined as weight (kg) divided by height squared $\left(\mathrm{m}^{2}\right)$.

Laboratory analyses Serum calcium was analysed within a week of sampling using an automated analyser (Hitachi 917) with reagents from Boehringer Mannheim. The reference range was $2.20-2.60 \mathrm{mmol} / \mathrm{l}$. Serum parathyroid hormone (PTH) was analysed in 2001 in a subgroup of 3277 participants using an automated clinical chemical analyser (Immulite 2000, Siemens Healthcare Diagnostics, Los Angeles, CA, USA), with a reference range of $1.1-6.8 \mathrm{pmol} / \mathrm{l}(\leq 50$ years) and $1.1-7.5 \mathrm{pmol} / \mathrm{l}$ (>50 years).

Sera from the second visit of the study were stored at $-70{ }^{\circ} \mathrm{C}$, and after a median storage time of 13 years, they were thawed in March 2008 and analysed for $25(\mathrm{OH}) \mathrm{D}_{3}$ by ECLIA (Roche) using an automated clinical chemistry analyser (Modular E170, Roche Diagnostics). The total analytical coefficient of variation (CV) for the $25(\mathrm{OH}) \mathrm{D}_{3}$ assay was $7.3 \%$ as recorded by measuring a donor control $(65.0 \mathrm{nmol} / \mathrm{l})$ consecutively during the analytical period using a quality management programme (QM, Tieto Enator, Helsinki, Finland). This was in accordance with the total analytical precision $\leq 7.8 \%$ as reported by the producer. The cross-reactivity with $25(\mathrm{OH}) \mathrm{D}_{2}$ was $<10 \%$, and the lower detection limit was $10 \mathrm{nmol} / \mathrm{l}$. Five subjects had $25(\mathrm{OH}) \mathrm{D}_{3}$ below the detection limit, and their value was set to $5 \mathrm{nmol} / \mathrm{l}$. All analyses were performed at the Department of Medical Biochemistry, University Hospital of North Norway, Tromsø, and were approved by the Norwegian Accreditation Authority.

\section{The validation study}

Study population The validation study was performed as an extension of the sixth survey of the Tromsø study, which included 12984 participants during 2007-2008 (attendance rate $65.7 \%$ ). Here, a 
questionnaire covering lifestyle factors was filled in by the participants at home, and it was checked for incomplete answers when they came for the first visit. Based on the information obtained from the questionnaire, a random group of participants matching the following predefined criteria was invited by mail to participate in the validation study:

i) 'Non-smokers' as defined by never smoked or quitted smoking $\geq 5$ years ago, or

ii) 'smokers' as defined by smoking $\geq 5$ cigarettes/day.

Subjects reporting use of snuff were not invited. We included 108 participants. The validation study was approved by the Regional Committee of Research Ethics, and each participant gave a written informed consent prior to the examination.

Measurements The participants in the validation study filled in a new questionnaire covering sex, age, smoking and snuffing habits, hours spent outdoors during the last week, use of solarium during the last 3 months and the last 14 days, sunny holidays during the last 3 months, intake of fatty fish as dinner or as a topping on sandwiches, intake of semi-skimmed milk (which is the only vitamin D-fortified milk in Norway), use of vitamin D supplementation, and self-reported height and weight. The questionnaire was checked for incomplete answers, and blood samples were taken by trained health personnel at the University Hospital of North Norway. Time since intake of last meal and smoking of last cigarette was noted, as well as the number of cigarettes smoked on the same day. The data collection was performed during a period of 3 weeks in April/May 2009.

Blood samples were obtained in SST gel tubes and centrifuged within $1 \mathrm{~h}$, and serum calcium, creatinine, phosphate and plasma PTH were analysed continuously. For analyses of serum $25(\mathrm{OH}) \mathrm{D}$, sera were divided into portions of $0.5 \mathrm{ml}$, and frozen in 1-ml Cryotube vials at $-70{ }^{\circ} \mathrm{C}$ for later analyses. Transportation to different laboratories was done on ice packs, and all samples were confirmed to be frozen at arrival by the receiving laboratories, and thus there were no thawing-freezing cycles.

Laboratory analyses Serum calcium and PTH in plasma were analysed within $24 \mathrm{~h}$ using methods that were the same as those used in the Tromsø study. Serum creatinine was analysed by an enzymatic colorimetric method (CREA plus, Roche Diagnostics) using an automated clinical chemistry analyser (Modular $\mathrm{P}$, Roche Diagnostics). Reference range was 50-90 $\mu \mathrm{mol} / \mathrm{l}$ for females and 60-100 $\mu \mathrm{mol} / \mathrm{l}$ for males. Serum phosphate was analysed by photometry using an automated clinical chemistry analyser (Modular P, Roche Diagnostics). Reference interval was $0.85-1.50 \mathrm{mmol} / \mathrm{l}$ for women aged $\geq 18$ years, $0.75-1.65 \mathrm{mmol} / \mathrm{l}$ for men aged 18-49 years and $0.75-1.35 \mathrm{mmol} / \mathrm{l}$ for men aged $\geq 50$ years. These analyses are approved by the Norwegian Accreditation Authority.
Serum 25(OH)D was analysed by the following six methods:

i) LC-MS/MS (Tromsø): serum 25(OH)D 3 was analysed by mass spectrometry using an isotope dilution LC-MS/MS assay adapted from Maunsell et al. (23). Briefly, serum samples were denatured with methanol-propanol containing a stable isotope-labelled internal standard, and thereafter, they were extracted into hexane and dried under nitrogen. The reconstituted extract was chromatographed on an HPLC column, and the vitamin D metabolite and internal standard were detected by electrospray ionisation MS/MS (Quattro Premier, Waters, Manchester, UK). There was no crossreactivity between vitamin $25(\mathrm{OH}) \mathrm{D}_{2}$ and vitamin $25(\mathrm{OH}) \mathrm{D}_{3}$ in the assay, and inter-assay $\mathrm{CV}$ was $\leq 6 \%$. The analyses were performed at the Department of Medical Biochemistry, University Hospital of North Norway, Tromsø.

ii) LC-MS/MS (Bergen): the isotope dilution tandem mass spectrometry method was developed at the Hormone Laboratory, Haukeland University Hospital, Bergen, Norway. In brief, serum was extracted with $n$-hexane:isopropanol, and injected into an isocratic HPLC system coupled with a API 3000 mass spectrometer (Applied Biosystems/MDS Sciex, Foster City, CA, USA) equipped with an electrospray source. The within-day precision (CV) was $\leq 3.1 \%$, and the between-day precision $(\mathrm{CV})$ was $\leq 8.7 \%$. There was no known interference from other substances, including no cross-reaction with vitamin $25(\mathrm{OH}) \mathrm{D}_{2}$.

iii) RIA (DiaSorin, Stillwater, MN, USA): serum levels of 25(OH)D were measured by RIA (DiaSorin) at the Hormone Laboratory, Department of Endocrinology, Oslo University Hospital, Norway. This assay measures both $25(\mathrm{OH}) \mathrm{D}_{3}$ and $25(\mathrm{OH}) \mathrm{D}_{2}$, and the total analytical $\mathrm{CV}$ was $14 \%$.

iv) HPLC: HPLC analyses were carried out using the manufacturer's reagent kit consisting of a mobile phase, calibrator, column, internal standard, and precipitation reagent and solid-phase extraction procedure (Chromsystems GmbH, 81243 München, Germany) at the Department of Clinical Chemistry, Akershus University Hospital, Lørenskog, Norway. Liquid chromatography was performed on a Shimadzu HPLC system (Shimadzu Corporation, Kyoto, Japan). The CV for the assay was $\leq 9.5 \%$.

v) RIA (IDS): the RIA method from Immuno Diagnostic Systems Nordic AS (IDS, Herlev, Denmark) performed at the Hormone Laboratory, Haukeland University Hospital, Bergen, Norway, had an inter-assay precision $(\mathrm{CV}) \leq 11.6 \%$. $25(\mathrm{OH}) \mathrm{D}_{2}$ had a $75 \%$ cross-reactivity with vitamin $25(\mathrm{OH}) \mathrm{D}_{3}$.

vi) ECLIA (Roche): see laboratory analyses under the Tromsø study. 
Table 1 Baseline characteristics of the study population in the Troms $ø$ study, 1994-1995. If not otherwise stated, values are shown as mean \pm s.D. Differences in characteristics between categories were compared with $\chi^{2}$ tests or ANOVA.

\begin{tabular}{lcccc}
\hline & All participants & Never smokers & Former smokers & Current smokers \\
\hline Females/males $(n)$ & $4230 / 2702$ & $1847 / 510^{*, \neq}$ & $1022 / 1258^{\ddagger}$ & $1361 / 934$ \\
Age as on December 31, 1994 (years) & $59.0 \pm 10.2$ & $59.0 \pm 10.9^{*, \neq}$ & $60.7 \pm 9.0^{\ddagger}$ & $57.3 \pm 10.2$ \\
BMl (kg/m ${ }^{2}$ ) & $26.0 \pm 4.1$ & $26.5 \pm 4.3^{\ddagger}$ & $26.6 \pm 3.7^{\ddagger}$ & $24.8 \pm 3.8$ \\
Physical activity (h/week) & $2.7 \pm 1.6$ & $2.7 \pm 1.5^{\dagger, \ddagger}$ & $2.8 \pm 1.6^{\ddagger}$ & $2.5 \pm 1.6$ \\
Vitamin D supplements (\%) & 43 & $46^{\ddagger}$ & $45^{\ddagger}$ & 39 \\
Serum 25(OH)D (nmol/l) & $58.9 \pm 20.2$ & $50.9 \pm 15.9^{*, \neq}$ & $53.5 \pm 17.3^{\ddagger}$ & $72.4 \pm 20.0$ \\
Serum 25(OH)D (nmol/l), adjusted & & $51.2 \pm 17.0^{*, \neq}$ & $53.6 \pm 17.0^{\ddagger}$ & $72.0 \pm 16.9$ \\
Serum calcium (mmol/l) & $2.37 \pm 0.11$ & $2.37 \pm 0.11$ & $2.37 \pm 0.11^{\S}$ & $2.38 \pm 0.11$ \\
Serum PTH measured (n) & 3180 & 1067 & 1073 & 1040 \\
Serum PTH (pmol/l) (median & $2.6(0.9,6.2)$ & $2.7(1.0,6.6)^{\ddagger}$ & $2.8(1.0,6.3)^{\ddagger}$ & $2.3(0.8,5.3)$ \\
$\quad(2.5,97.5$ percentile range)) & & & &
\end{tabular}

BMI, body mass index; 25(OH)D, 25-hydroxyvitamin D; PTH, parathyroid hormone. ${ }^{\star} P<0.01,{ }^{\dagger} P<0.05$ compared with former smokers; ${ }^{\ddagger} P<0.01,{ }^{\S} P<0.05$ compared with current smokers.

${ }^{a}$ Adjusted for age, sex, month of blood sampling, vitamin D supplementation (yes/no), BMI and physical activity level.

\section{Statistical analyses}

The Tromso study Distribution of the variables was evaluated by visual inspection of histograms for skewness and kurtosis, and after log-transforming PTH, the distributions of all dependent variables were considered normal. Differences between means of continuous variables of current, former and never smokers were assessed by ANOVA with the Bonferroni correction, while differences in the distribution of categorical variables were assessed by $\chi^{2}$ tests. Since age, sex, BMI, vitamin D supplementation and physical activity differed between the groups and correlated with serum 25(OH)D levels (data not shown), we estimated adjusted means of serum 25(OH)D for each month of blood sampling using a general linear model with age, sex, BMI, physical activity level and vitamin D supplementation as covariates. Owing to the general vacation in Norway in July, data from this month were not obtained, and a mean value for this month was estimated by adding the mean levels for June and August divided by 2 for use in the figures. The variables 'years of smoking', 'number of cigarettes' and 'years since smoking cessation' were grouped into categories, and linear trends in 25(OH)D levels were assessed using a general linear model including the same covariates as

Table 2 Serum 25(OH)D levels in relation to reported years of smoking and number of cigarettes smoked and years since smoking cessation in former and current smokers in the Tromsø study, 1994-1995.

\begin{tabular}{|c|c|c|c|c|c|c|}
\hline & \multicolumn{3}{|c|}{ Former smokers } & \multicolumn{3}{|c|}{ Current smokers } \\
\hline & $n^{\mathrm{a}}$ & $\begin{array}{l}\text { Serum } 25(\mathrm{OH}) \\
\mathrm{D}(\mathrm{nmol} / \mathrm{l})^{\mathrm{b}}\end{array}$ & $95 \% \mathrm{Cl}$ & $n^{\mathrm{a}}$ & $\begin{array}{l}\text { Serum } 25(\mathrm{OH}) \\
\mathrm{D}(\mathrm{nmol} /)^{\mathrm{b}}\end{array}$ & $95 \% \mathrm{Cl}$ \\
\hline \multicolumn{7}{|c|}{ Years of smoking } \\
\hline $1-10$ & 503 & 52.1 & $50.7-53.6$ & 77 & 59.9 & $55.5-64.3$ \\
\hline $11-20$ & 686 & 53.7 & $52.6-54.9$ & 269 & 68.7 & $66.0-71.3$ \\
\hline $21-30$ & 548 & 53.6 & $52.3-54.9$ & 517 & 71.1 & $69.5-72.8$ \\
\hline $31-40$ & 347 & 55.3 & $53.6-57.0$ & 784 & 73.9 & $72.6-75.2$ \\
\hline$>40$ & 173 & 53.8 & $51.3-56.2$ & 640 & 74.8 & $73.0-76.6$ \\
\hline$P$ for trend ${ }^{c}$ & & 0.11 & & & $<0.01$ & \\
\hline \multicolumn{7}{|c|}{ Number of cigarettes/day } \\
\hline $1-5$ & 431 & 53.9 & $52.4-55.5$ & 296 & 67.5 & $65.4-69.7$ \\
\hline $6-10$ & 863 & 53.1 & $52.0-54.1$ & 942 & 72.3 & $71.0-73.5$ \\
\hline $11-20$ & 678 & 54.0 & $52.8-55.2$ & 860 & 74.2 & $72.9-75.5$ \\
\hline$>20$ & 177 & 53.4 & $51.0-55.8$ & 103 & 78.5 & $74.8-82.3$ \\
\hline$P$ for trend ${ }^{c}$ & & 0.64 & & & $<0.01$ & \\
\hline \multicolumn{7}{|c|}{ Years since smoking cessation } \\
\hline $1-2$ & 246 & 55.5 & $53.5-57.5$ & & & \\
\hline $3-5$ & 238 & 54.9 & $52.9-56.9$ & & & \\
\hline$>5$ & 1796 & 53.1 & $52.3-53.8$ & & & \\
\hline$P$ for trend ${ }^{c}$ & & 0.03 & & & & \\
\hline
\end{tabular}

BMI, body mass index; Cl, confidence interval; 25(OH)D, 25-hydroxyvitamin D.

${ }^{a}$ Numbers may not sum to the same total in the corresponding columns due to missing data on smoke exposure.

${ }^{b}$ Values are means adjusted for age, sex, month of blood sampling, vitamin D supplementation (yes/no), BMI and physical activity level.

${ }^{\mathrm{c}}$ Tests for trends across categories were performed using a general linear model with adjustment for the same factors as mentioned above. 


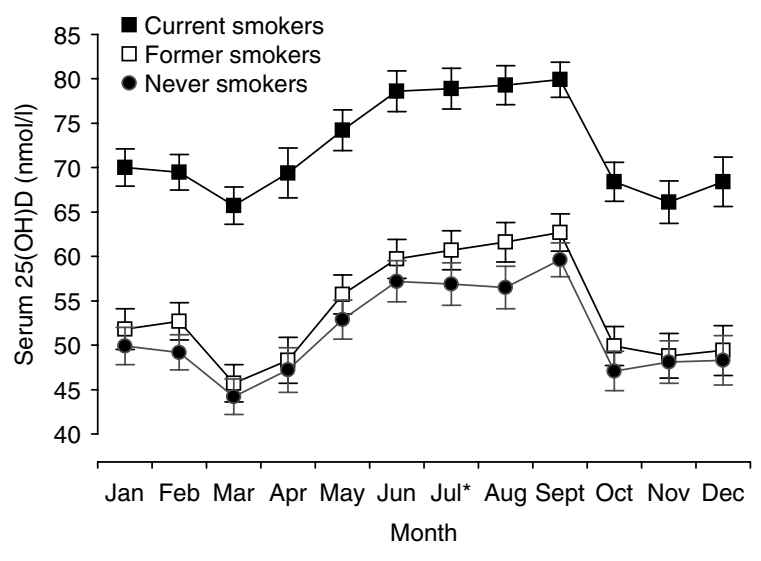

Figure 1 Serum 25(OH)D levels throughout the year in 2357 never smokers, 2280 former smokers and 2295 current smokers in the Tromsø study, 1994-1995. The values are shown as means and $95 \%$ confidence intervals adjusted for age, sex, vitamin D supplementation (yes/no), physical activity level and body mass index. *Values for the month of July are estimated based on the means of June and August.

mentioned above. All tests were done two-sided, and $P<0.05$ was considered statistically significant. Statistical analyses were performed with SPSS version 14.0 (SPSS Inc., Chicago, IL, USA).

The validation study Background characteristics of smokers and non-smokers were compared by Student's $t$-test or $\chi^{2}$ tests. Correlation coefficients, simple scatter plots and Bland-Altman plots were used to compare the methods. A linear mixed model was used to assess the effect of smoking between laboratory methods for 25(OH)D. Smoking (yes/no) and indicator variables of each laboratory method and an interaction term between smoking and each indicator variable of laboratory method comprised the fixed effects part of the model, whereas a random effect for each subject and a residual term for within-subject variation comprised the random part of the model. All tests were done twosided, and $P<0.05$ was considered statistically significant. Statistical analyses were performed with SPSS version 16.0 (SPSS Inc).

\section{Results}

\section{The Tromso study}

Complete data sets were available in 4230 women and 2702 men. Characteristics of the whole group and those according to smoking status are given in Table 1. The main finding was the substantially higher serum $25(\mathrm{OH}) \mathrm{D}$ levels in current smokers than in never smokers, with former smokers exhibiting slightly higher levels than never smokers (Table 1). The differences in the serum 25(OH)D levels between never, former and current smokers remained almost unchanged after correction for the confounders age, sex, physical activity level, vitamin D supplementation, month of blood sampling and BMI (Table 1). The serum levels of $25(\mathrm{OH}) \mathrm{D}$ increased with reported years of smoking and number of cigarettes smoked per day in current smokers, but not in former smokers (Table 2). However, there was a minor decrease in serum $25(\mathrm{OH}) \mathrm{D}$ levels with increasing years since smoking cessation in former smokers (Table 2). Separate analyses of the small groups of exclusively pipe smokers $(n=46)$ and cigar/cigarillo $(n=19)$ smokers showed higher serum 25(OH)D levels compared with never smokers (70.7 and 85.2 vs $50.9 \mathrm{nmol} / \mathrm{l}, \mathrm{P}<0.001$ for both comparisons). Current, former and never smokers showed similar seasonality in

Table 3 Baseline characteristics of the study population in the validation study, 2009. If not otherwise stated, values are shown as mean \pm s.D. Differences in characteristics between smokers and non-smokers were compared with Student's $t$-tests or $\chi^{2}$-tests.

\begin{tabular}{|c|c|c|c|}
\hline & All & Non-smokers & Smokers \\
\hline Females/males $(n)$ & $63 / 44$ & $33 / 20$ & $30 / 24$ \\
\hline Age (years) & $55.9 \pm 12.4$ & $56.9 \pm 13.0$ & $54.9 \pm 11.8$ \\
\hline BMI $\left(\mathrm{kg} / \mathrm{m}^{2}\right)^{\mathrm{a}}$ & $25.9 \pm 3.8$ & $25.8 \pm 3.9$ & $26.0 \pm 3.7$ \\
\hline Sunny holiday during the last 3 months (yes/no) & $13 / 94$ & $5 / 48$ & $8 / 46$ \\
\hline Use of solarium during the last 14 days (yes/no) & $5 / 102$ & $2 / 51$ & $3 / 51$ \\
\hline Use of solarium during the last 3 months (yes/no) & $14 / 93$ & $5 / 48$ & $9 / 45$ \\
\hline Hours spent outdoors in the last 7 days & $13.7 \pm 10.0$ & $12.7 \pm 8.6$ & $14.6 \pm 11.3$ \\
\hline Fatty fish $\geq 1 /$ week (yes/no) & $55 / 52$ & $25 / 28$ & $30 / 24$ \\
\hline Semi-skimmed milk ${ }^{\mathrm{b}} \geq 1 /$ day $\left(\right.$ yes $/$ no) ${ }^{\mathrm{a}}$ & $30 / 76$ & $19 / 34$ & $11 / 42$ \\
\hline Daily vitamin D supplementation (yes/no) & $39 / 68$ & $23 / 30$ & $16 / 38$ \\
\hline Serum calcium (mmol/l) & $2.35 \pm 0.09$ & $2.35 \pm 0.12$ & $2.35 \pm 0.07$ \\
\hline Serum phosphate (mmol/l) & $1.17 \pm 0.19$ & $1.20 \pm 0.18$ & $1.15 \pm 0.20$ \\
\hline Serum creatinine $(\mu \mathrm{mol} / \mathrm{l})$ & $69.9 \pm 12.8$ & $71.3 \pm 13.3$ & $68.4 \pm 12.2$ \\
\hline Plasma PTH (pmol/l) & $5.4 \pm 1.3$ & $5.6 \pm 1.2$ & $5.2 \pm 1.4$ \\
\hline Years of smoking & & & $33.0 \pm 13.5$ \\
\hline Number of cigarettes/day & & & $12.1 \pm 4.7$ \\
\hline Number of cigarettes/examination day & & & $5.4 \pm 3.0$ \\
\hline
\end{tabular}

BMI, body mass index; PTH, parathyroid hormone.

aData available in 106 participants.

${ }^{\text {b } V i t a m i n ~ D-f o r t i f i e d ~ m i l k . ~}$ 
Table 4 Serum 25-hydroxyvitamin D measurement with different methods in the validation study, 2009.

\begin{tabular}{|c|c|c|c|c|}
\hline & \multicolumn{3}{|c|}{ Serum 25(OH)D (nmol/l) (mean \pm s.D.) } & \multirow{2}{*}{$\begin{array}{c}\text { Difference in serum } \\
25(\mathrm{OH}) \mathrm{D}(\mathrm{nmol} / \mathrm{l}) \text {, mean } \\
(95 \% \mathrm{Cl}) ; \text { smokers } \\
\text { versus non-smokers }\end{array}$} \\
\hline & All & Non-smokers & Smokers & \\
\hline$n$ & 107 & 53 & 54 & \\
\hline LC-MS/MS (Tromsø) & $55.6 \pm 22.7$ & $56.8 \pm 23.0$ & $54.5 \pm 22.4$ & $-2.3(-11.0,6.4)^{\dagger}$ \\
\hline LC-MS/MS (Bergen) & $65.0 \pm 26.0$ & $66.1 \pm 26.3$ & $64.0 \pm 25.9$ & $-2.2(-12.2,7.8)^{\dagger}$ \\
\hline RIA (DiaSorin) & $58.2 \pm 21.1$ & $59.6 \pm 20.2$ & $56.8 \pm 22.0$ & $-2.8(-10.9,5.3)^{\dagger}$ \\
\hline HPLC & $65.2 \pm 25.5$ & $67.2 \pm 24.6$ & $63.2 \pm 26.4$ & $-4.0(-13.8,5.7)^{\dagger}$ \\
\hline RIA (IDS) & $62.6+20.2$ & $64.0+19.1$ & $61.1+21.2$ & $-2.9(-10.6,4.9)^{\dagger}$ \\
\hline ECLIA (Roche) & $61.4 \pm 16.5$ & $56.2 \pm 14.2$ & $66.5 \pm 17.2$ & $10.3(4.2,16.3)^{*}$ \\
\hline
\end{tabular}

Difference in serum 25-hydroxyvitamin $D$ between smokers and non-smokers within each method was assessed by Student's $t$-test, while difference between methods was assessed using a linear mixed model with method and smoking status as factors. ${ }^{*}$ Difference in smokers versus non-smokers, $P=0.001$.

${ }^{\dagger}$ Difference between methods, ECLIA (Roche) as reference, $P<0.001$.

25(OH)D levels, and the mean difference of about $3 \mathrm{nmol} / \mathrm{l}$ between former and never smokers and about $21 \mathrm{nmol} / \mathrm{l}$ between current and never smokers remained stable throughout the year (Fig. 1). The greatest peak was observed in September, and the nadir was observed in March for all groups. When males and females were analysed separately, the results were essentially the same (data not shown).

\section{The validation study}

After exclusion of one subject who had quitted smoking 3 months before examination and therefore did not fulfil the inclusion criteria, we had available data in 107 subjects: 54 smokers and 53 non-smokers. As presented in Table 3, background characteristics did not differ between smokers and non-smokers. Although not statistically significant, five of the methods reported lower serum $25(\mathrm{OH}) \mathrm{D}$ levels in smokers than in non-smokers (Table 4). However, using the ECLIA (Roche) method, smokers had significantly higher serum 25(OH)D levels than non-smokers, and this method differed significantly from the other methods regarding the effects of smoking (Table 4). The correlations between the different methods were generally very high (Table 5), although the correlations between the ECLIA (Roche) and the other methods were somewhat lower (Table 5). When analysing non-smokers separately, the correlation between the ECLIA (Roche) and the other methods improved (Table 6), without reaching the same level of agreement as that observed between other methods. The same was observed when analysing smokers separately (data not shown). To illustrate a typical relationship between two methods, a simple scatter plot and a Bland-Altman plot are shown in Figs 2 and 3, while similar plots including the ECLIA (Roche) method are shown in Figs 4 and 5. The other plots are available on request. In smokers, time since smoking of last cigarette varied from 4 to $370 \mathrm{~min}$ with a median of $45 \mathrm{~min}$. The correlation between time since smoking of last cigarette in smokers and serum $25(\mathrm{OH}) \mathrm{D}$ concentration was non-significant (Pearson's correlation coefficient: $-0.07, P=0.60$ ).

\section{Discussion}

We have performed one population-based study and one validation study, which together indicate an impact of smoking on the results of serum 25(OH)D analyses using the ECLIA (Roche) method, revealing relatively higher levels of serum 25(OH)D in smokers than what are found with other methods presently in use. This assay has previously been compared with both immunological and mass spectrometric methods of $25(\mathrm{OH}) \mathrm{D}$ measurement, and a good overall agreement

Table 5 Pearson's correlation coefficient between the different methods for serum 25-hydroxyvitamin D measurements in 107 subjects (53 non-smokers and 54 smokers) in the validation study, 2009.

\begin{tabular}{|c|c|c|c|c|c|c|}
\hline & $\begin{array}{l}\text { LC-MS/MS } \\
\text { (Troms } \varnothing \text { ) }\end{array}$ & $\begin{array}{l}\text { LC-MS/MS } \\
\text { (Bergen) }\end{array}$ & $\begin{array}{l}\text { RIA } \\
\text { (DiaSorin) }\end{array}$ & HPLC & RIA (IDS) & $\begin{array}{l}\text { ECLIA } \\
\text { (Roche) }\end{array}$ \\
\hline LC-MS/MS (Tromsø) & 1 & & & & & \\
\hline LC-MS/MS (Bergen) & $0.98^{*}$ & 1 & & & & \\
\hline RIA (DiaSorin) & $0.94^{\star}$ & $0.96^{\star}$ & 1 & & & \\
\hline HPLC & $0.94^{*}$ & $0.94^{*}$ & $0.96^{*}$ & 1 & & \\
\hline RIA (IDS) & $0.93^{\star}$ & $0.94^{*}$ & $0.95^{*}$ & $0.92^{*}$ & 1 & \\
\hline ECLIA (Roche) & $0.75^{\star}$ & $0.77^{\star}$ & $0.78^{*}$ & $0.75^{\star}$ & $0.76^{\star}$ & 1 \\
\hline
\end{tabular}

${ }^{*} P<0.01$. 
Table 6 Pearson's correlation coefficient between the different methods for serum 25-hydroxyvitamin D measurements in 53 non-smokers in the validation study, 2009.

\begin{tabular}{|c|c|c|c|c|c|c|}
\hline & $\begin{array}{l}\text { LC-MS/MS } \\
\text { (Troms } \varnothing)\end{array}$ & $\begin{array}{l}\text { LC-MS/MS } \\
\text { (Bergen) }\end{array}$ & $\begin{array}{l}\text { RIA } \\
\text { (DiaSorin) }\end{array}$ & HPLC & RIA (IDS) & ECLIA (Roche) \\
\hline LC-MS/MS (Tromsø) & 1 & & & & & \\
\hline LC-MS/MS (Bergen)' & $0.99^{*}$ & 1 & & & & \\
\hline RIA (DiaSorin) & $0.93^{*}$ & $0.94^{*}$ & 1 & & & \\
\hline HPLC & $0.95^{*}$ & $0.96 *$ & $0.98^{*}$ & 1 & & \\
\hline RIA (IDS) & $0.94^{*}$ & $0.95^{*}$ & $0.95^{\star}$ & $0.95^{\star}$ & 1 & \\
\hline ECLIA (Roche) & $0.81^{*}$ & $0.80^{*}$ & $0.83^{*}$ & $0.81^{*}$ & $0.83^{*}$ & 1 \\
\hline
\end{tabular}

has been reported (24-26). However, the authors did not report data regarding smoking, and to our knowledge, this has not been studied previously using the ECLIA (Roche) method. If confirmed, this finding has clinically relevant consequences for many smoking patients who might have missed the diagnosis of easily treatable hypovitaminosis D. This is particularly unfortunate as smokers also have a higher risk of osteoporotic fractures (27), which might be prevented by the correction of hypovitaminosis D.

The data obtained from the Tromsø study were consistent in showing a higher serum 25(OH)D level throughout the year in current smokers than in never smokers using the ECLIA (Roche) method. The results also indicated a dose-response relationship as former smokers were close to, but still had higher serum $25(\mathrm{OH}) \mathrm{D}$ concentrations, than never smokers. In addition, the serum levels of $25(\mathrm{OH}) \mathrm{D}$ increased with increasing years of smoking and with increasing number of cigarettes smoked per day, while serum 25(OH)D decreased with increasing time since smoking cessation. Other studies registering data on smoking and serum levels of 25(OH)D report either lower levels (the difference ranging from 4 to $15 \mathrm{nmol} / \mathrm{l}$ ) of $25(\mathrm{OH}) \mathrm{D}$ in smokers (3-10), or no statistically significant difference between smokers and non-smokers regarding serum 25(OH)D levels (11-20). The only exception we are aware of is an American study of 805 women aged 18-33 years, where smokers had higher serum $25(\mathrm{OH}) \mathrm{D}$ levels than non-smokers $(58.43 \mathrm{nmol} / \mathrm{l}$ compared with $48.99 \mathrm{nmol} / \mathrm{l}, \quad P<0.0001)$ (21). However, following multiple adjustments, smoking did not affect the serum levels of 25(OH)D (21). All these studies used various forms of immunometric methods, although not the ECLIA (Roche) method (3-21).

The highest serum $25(\mathrm{OH}) \mathrm{D}$ levels were observed at the end of summer, and the difference between the peak value in September and the nadir value in March reached $14.2 \mathrm{nmol} / \mathrm{l}$ in current smokers, $17.0 \mathrm{nmol} / \mathrm{l}$ in former smokers and $15.3 \mathrm{nmol} / \mathrm{l}$ in never smokers. These differences between peak and nadir values are in accordance with studies in more sunny countries $(11,14,28,29)$; furthermore, it is consistent with the location of Tromsø at $69.7^{\circ} \mathrm{N}$, where the period of the year with UVB radiation below the threshold for vitamin D production in the skin is from the end of September till the middle of March (30).

In the validation study, we confirmed the finding that smokers had higher serum 25(OH)D levels than non-smokers when the levels were measured with the ECLIA (Roche) method, and that the ECLIA (Roche) method differed significantly from the other five methods in this aspect, as they all showed lower (although not significant) serum levels of $25(\mathrm{OH}) \mathrm{D}$ in smokers. Although the difference between smokers and non-smokers using the ECLIA (Roche) was not of the same magnitude in the validation study as in the Tromsø study, the difference still comprised more than $10 \mathrm{nmol} / \mathrm{l}$. We do not know why these results differed, but the validation study was much smaller $(n=107$ vs 6932 ), and the cohort was younger than that in the Tromsø study (55.9 vs 59.0 years). In addition, the current smokers in the Tromsø study had lower BMI than never smokers $\left(24.1\right.$ vs $\left.26.5 \mathrm{~kg} / \mathrm{m}^{2}\right)$, while the

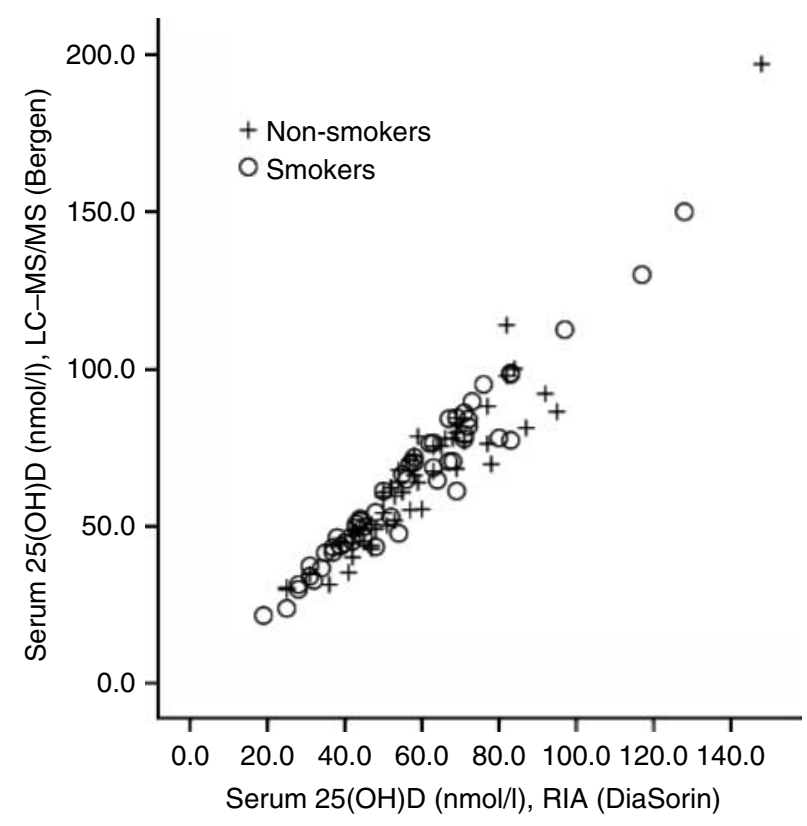

Figure 2 Scatter plot between RIA (DiaSorin) assay for serum 25(OH)D and LC-MS/MS (Bergen) by smoking status in the validation study, 2009. 


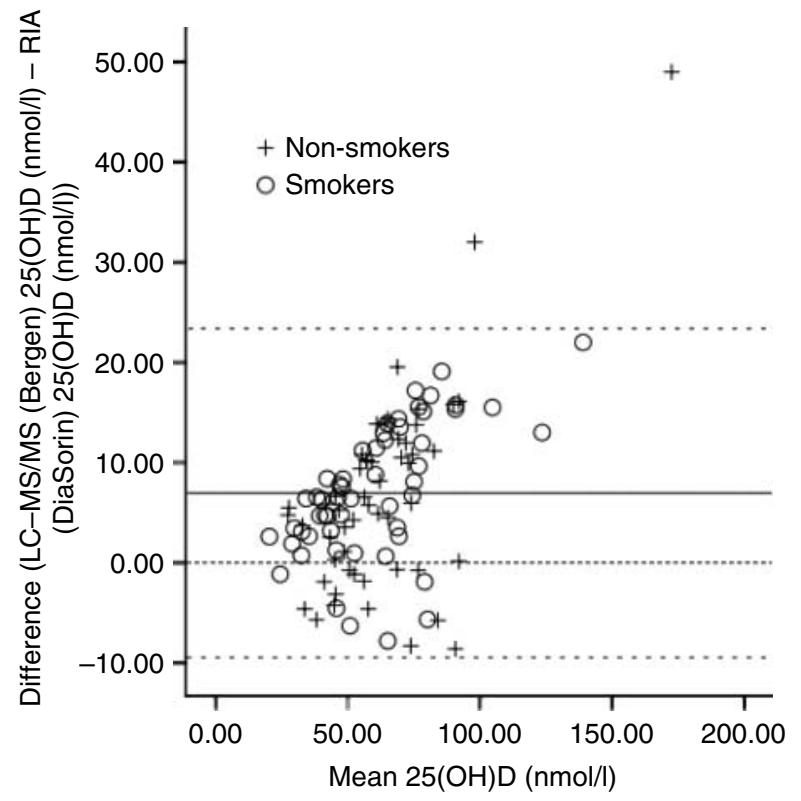

Figure 3 Bland-Altman plot where the $x$-axis indicates the mean of serum 25(OH)D measured with RIA (DiaSorin) and LC-MS/MS (Bergen) in 54 individual smokers and 53 individual non-smokers and the $y$-axis indicates the difference between the corresponding individual measurements in the validation study, 2009. Dotted line represents the line of identity. The solid line represents the mean of paired differences. Dashed lines represent mean \pm 1.96 S.D.

BMI was similar among smokers and non-smokers in the validation study ( 26.0 vs $25.8 \mathrm{~kg} / \mathrm{m}^{2}$ ).

The dose dependency between smoking and serum 25(OH)D levels found in the Tromsø study suggests the presence of one or more substances that are dose dependently associated with smoking, which interferes with the separation agent, antibodies or vitamin D-binding protein in the ECLIA (Roche) assay, and thereby modulates the measurement of serum 25(OH)D. Cigarette smoke consists of more than 4000 different substances (31). In addition, cigarette smoking affects concentrations of other compounds in the body. For instance, both PTH $(6,12,32)$ and TSH $(33)$ have been reported to be lower in smokers, while oestrone and oestradiol levels appear to be higher in male smokers (34). Accordingly, both direct effects from compounds in smoke and indirect effects through changes in the concentrations of other physiological substances may be responsible for the overestimation. This phenomenon may also be valid in immunoassays in use for other analytes. Accordingly, we suggest that special attention be paid to the possible effects of smoking when current and new immunoassays are validated. However, as the present studies do not give any molecular explanation for this observation, this issue needs further exploration.

On the other hand, it could be that the ECLIA (Roche) method displays the most accurate serum 25(OH)D values, and that the problem is that the other methods underestimate serum 25(OH)D in smokers. If so, this could explain why plasma PTH levels are reported to be lower in smokers $(6,12,32)$, and it would also be consistent with the fact that moderate smokers are found to have lower BMI than non-smokers (35), as BMI and serum 25(OH)D levels are inversely correlated in most studies (36). However, in the validation study, there was no difference in BMI between smokers and non-smokers, and neither were there any differences in reported intake of vitamin D or in sun-seeking behaviour that could explain higher serum 25(OH)D levels in smokers. It is also unlikely that the totally different assay principles, such as chromatography, immunometry and mass spectrometry, should express similar systematic errors. Accordingly, we find it very unlikely that the ECLIA (Roche) method reveals the most accurate values in the smokers.

The high correlations between the assays were in agreement with previous findings $(24,25,37)$, but still, regardless of smoking, there were differences between the methods as illustrated by mean values and Bland-Altman plots. This is a well-known problem that might be attenuated by using internationally agreed standard calibrators to improve comparability between methods $(37,38)$.

The main strength of this study was the replication of the main finding in two different samples and study designs. Other strengths were the size and the yearround measurements in the Tromsø study and the thoroughness of the validation study where great efforts were made to avoid differences in sample handling

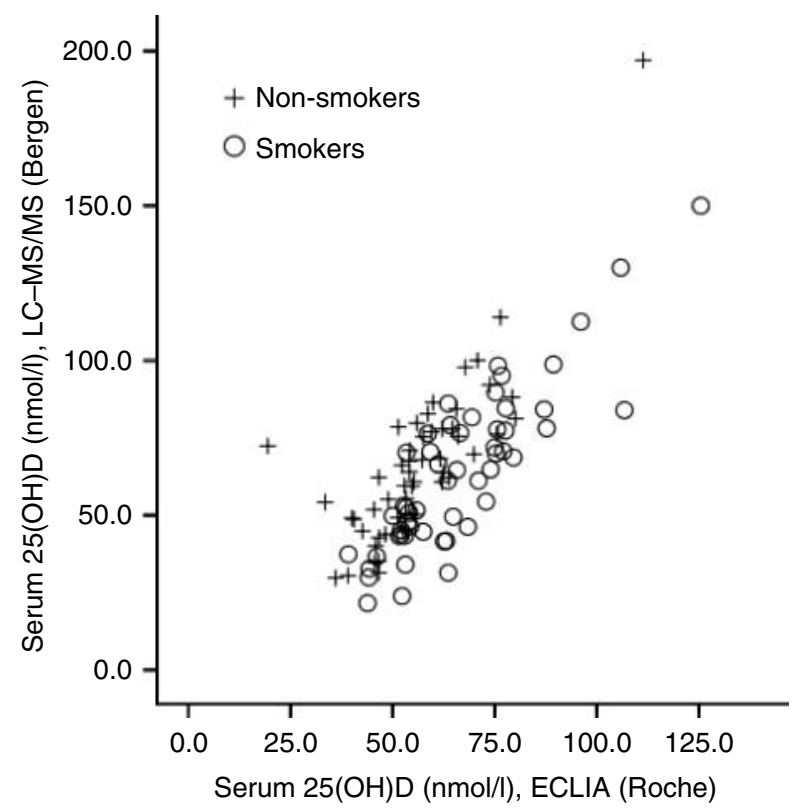

Figure 4 Scatter plot between ECLIA (Roche) assay for serum 25(OH)D and LC-MS/MS (Bergen) by smoking status in the validation study, 2009. 


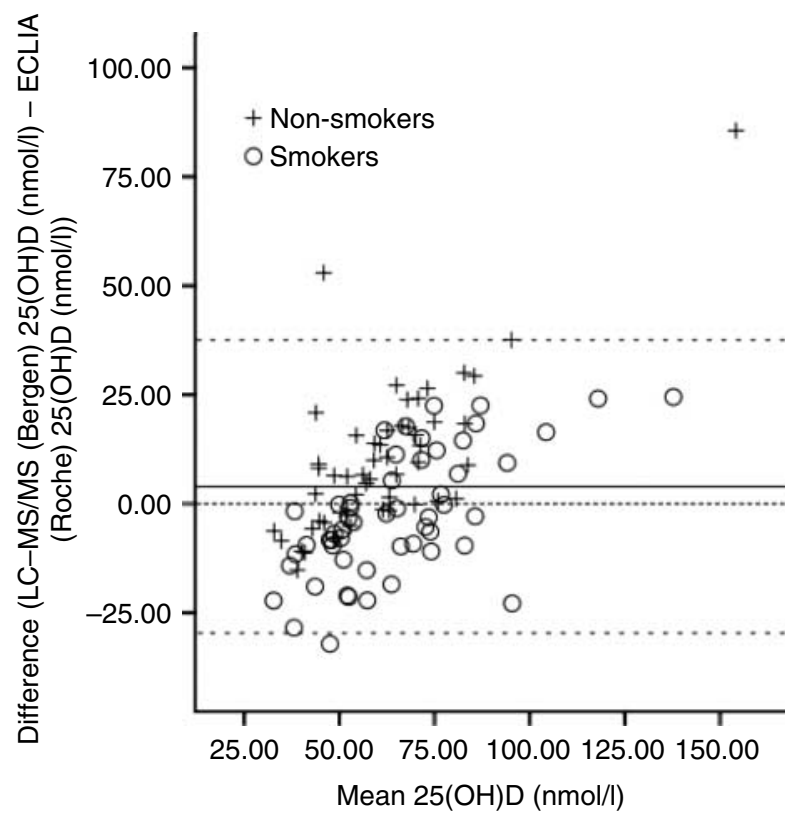

Figure 5 Bland-Altman plot where the $x$-axis indicates the mean of serum 25(OH)D measured with ECLIA (Roche) and LC-MS/MS (Bergen) in 54 individual smokers and 53 individual non-smokers and the $y$-axis indicates the difference between the corresponding individual measurements in the validation study, 2009. Dotted line represents the line of identity. The solid line represents the mean of paired differences. Dashed lines represent mean \pm 1.96 s.D.

before laboratory analyses. The main weakness is that the ECLIA (Roche) was performed in the same laboratory in both studies. It is, however, unlikely that the problem should be laboratory specific, as the ECLIA (Roche) is a fully automated method which diminishes the risk of user errors. Although the ECLIA (Roche) assay does not recognise serum $25(\mathrm{OH}) \mathrm{D}_{2}$, this is not a practical problem in these two studies, as all vitamin $\mathrm{D}$ fortification and over-the-counter supplementation in Norway consist of cholecalciferol. In addition, no $25(\mathrm{OH}) \mathrm{D}_{2}$ was observed by LC-MS/MS. Thus, differences in method specificities could not explain our findings. Another limitation of the study is that we cannot differentiate between acute and chronic effects of cigarette smoking on the serum $25(\mathrm{OH}) \mathrm{D}$ measurements, as the smokers were allowed to smoke before blood sampling. However, there was no correlation between time since smoking of last cigarette and serum 25(OH)D concentration as measured by ECLIA (Roche) in smokers, and also the impact of smoking on serum $25(\mathrm{OH}) \mathrm{D}$ concentration in former smokers in the Tromsø study makes it more likely that the effect is chronic rather than acute.

In conclusion, the results from these two studies indicate an impact of smoking on the measured serum levels of $25(\mathrm{OH})$ using the ECLIA (Roche) method compared with other methods in use. If confirmed, this might have considerable clinical consequences.
The mechanisms behind the finding need to be explored, and possible effects of smoking should also be considered in other immunoassays in light of these findings.

\section{Declaration of interest}

G Grimnes received a lecture honorarium of USD 375 from Roche Diagnostics in 2008.

\section{Funding}

This work was supported by the Norwegian Council of Cardiovascular Diseases, the Northern Norway Regional Health Authority and the Norwegian Women's Public Health Association in Troms County.

\section{Acknowledgements}

The staff at the Clinical Research Unit and Inger Myrnes, Astrid Lindvall and Ole Martin Sand at the Department of Medical Biochemistry, University Hospital of North Norway, are gratefully acknowledged for their superb assistance. We are grateful to the Tromsø study for providing us access to the data.

\section{References}

1 Hollis BW. Assessment of vitamin D status and definition of a normal circulating range of 25-hydroxyvitamin D. Current Opinion in Endocrinology, Diabetes and Obesity 200815 489-494.

2 Carter GD. 25-Hydroxyvitamin D assays: the quest for accuracy. Clinical Chemistry 200955 1300-1302.

3 Hermann AP, Brot C, Gram J, Kolthoff N \& Mosekilde L. Premenopausal smoking and bone density in 2015 perimenopausal women. Journal of Bone and Mineral Research 200015 780-787.

4 Szulc P, Garnero P, Claustrat B, Marchand F, Duboeuf F \& Delmas PD. Increased bone resorption in moderate smokers with low body weight: the Minos Study. Journal of Clinical Endocrinology and Metabolism $200287666-674$.

5 Lorentzon M, Mellström D, Haug E \& Ohlssson C. Smoking is associated with lower bone mineral density and reduced cortical thickness in young men. Journal of Clinical Endocrinology and Metabolism 200792 497-503.

6 Brot C, Jorgensen NR \& Sorensen OH. The influence of smoking on vitamin D status and calcium metabolism. European Journal of Clinical Nutrition 199953 920-926.

7 Lamberg-Allardt CJ, Outila TA, Kärkkainen MU, Rita HJ \& Valsta LM. Vitamin D deficiency and bone health in healthy adults in Finland: could this be a concern in other parts of Europe? Journal of Bone and Mineral Research 200116 2066-2073.

8 Rapuri PB, Gallagher JC, Balhorn KE \& Ryschon KL. Smoking and bone metabolism in elderly women. Bone 200027 429-436.

9 Laaksi I, Ruohola JP, Tuohimaa P, Auvinen A, Haataja R, Pihlajamäki $\mathrm{H} \&$ Ylikomi T. An association of serum vitamin D concentrations $<40 \mathrm{nmol} / \mathrm{L}$ with acute respiratory tract infection in young Finnish men. American Journal of Clinical Nutrition 2007 $86714-717$.

10 Harris SS, Soteriades E, Coolidge JA, Mudgal S \& DawsonHughes B. Vitamin D insufficiency and hyperparathyroidism in a low income, multiracial, elderly population. Journal of Clinical Endocrinology and Metabolism 200085 4125-4130.

11 Arunabh S, Pollack S, Yeh J \& Aloia JF. Body fat content and 25-hydroxyvitamin D levels in healthy women. Journal of Clinical Endocrinology and Metabolism $2003 \mathbf{8 8}$ 157-161. 
12 Need AG, Kemp A, Giles N, Morris HA, Horowitz M \& Nordin BE. Relationships between intestinal calcium absorption, serum vitamin D metabolites and smoking in postmenopausal women. Osteoporosis International 200213 83-88.

13 Saquib N, von Mühlen D, Garland CF \& Barrett-Connor E. Serum 25-hydroxvitamin D, parathyroid hormone, and bone mineral density in men: the Rancho Bernardo study. Osteoporosis International $2006 \mathbf{1 7} 1734-1741$.

14 Jacques PF, Felson DT, Tucker KL, Mahnken B, Wilson PW, Rosenberg IH \& Rush D. Plasma 25-hydroxyvitamin D and its determinants in an elderly population sample. American Journal of Clinical Nutrition 199766 929-936.

15 Kimlin M, Harrison S, Nowak M, Moore M, Brodie A \& Lang C. Does a high UV environment ensure adequate vitamin D status? Journal of Photochemistry and Photobiology. B, Biology 2007 89 139-147.

16 Scragg R, Holdaway I, Jackson R \& Lim T. Plasma 25-hydroxyvitamin D3 and its relation to physical activity and other heart disease risk factors in the general population. Annals of Epidemiology 19922 697-703.

17 van Dam RM, Snijder MB, Dekker JM, Stehouwer CD, Bouter LM, Heine RJ \& Lips P. Potentially modifiable determinants of vitamin D status in an older population in the Netherlands: the Hoorn Study. American Journal of Clinical Nutrition 200785 755-761.

18 de Boer IH, Ioannou GN, Kestenbaum B, Brunzell JD \& Weiss NS. 25-Hydroxyvitamin D levels and albuminuria in the Third National Health and Nutrition Examination Survey (NHANES III). American Journal of Kidney Diseases 200750 69-77.

19 Knight JA, Vachon CM, Vierkant RA, Vieth R, Cerhan JR \& Sellers TA. No association between 25-hydroxyvitamin D and mammographic density. Cancer Epidemiology, Biomarkers and Prevention 200615 1988-1992.

20 Snijder MB, Lips P, Seidell JC, Visser M, Deeg DJ, Dekker JM \& van Dam RM. Vitamin D status and parathyroid hormone levels in relation to blood pressure: a population-based study in older men and women. Journal of Internal Medicine 2007261 558-565.

21 McKinney K, Breitkopf CR \& Berenson AB. Association of race, body fat and season with vitamin D status among young women: a cross-sectional study. Clinical Endocrinology $200869535-541$.

22 Berntsen GK, Fønnebø V, Tollan A, Søgaard AJ \& Magnus JH. Forearm bone mineral density by age in 7,620 men and women: the Tromsø Study, a population-based study. American Journal of Epidemiology $2001 \mathbf{1 5 3}$ 465-473.

23 Maunsell Z, Wright D \& Rainbow S. Routine isotope-dilution liquid chromatography-tandem mass spectrometry assay for simultaneous measurement of the 25-hydroxy metabolites of vitamins $\mathrm{D}_{2}$ and $\mathrm{D}_{3}$. Clinical Chemistry 200551 1683-1690.

24 Leino A, Turpeinen U \& Koskinen P. Automated measurement of 25-OH vitamin $\mathrm{D}_{3}$ on the Roche Modular E 170 analyzer. Clinical Chemistry $2008 \mathbf{5 4} 2059-2062$.

25 Wagner D, Hanwell HE \& Vieth R. An evaluation of automated methods for measurement of serum 25-hydroxyvitamin D. Clinical Biochemistry 200942 1549-1556.
26 Roth HJ, Scmidt-Gayk H, Weber H \& Niederau C. Accuracy and clinical implications of seven 25-hydroxyvitamin D methods compared with liquid chromatography-tandem mass spectrometry as a reference. Annals of Clinical Biochemistry $2008 \mathbf{4 3}$ 153-159.

27 Wong PK, Christie JJ \& Wark JD. The effects of smoking on bone health. Clinical Science 2007113 233-241.

28 Bodnar LM, Catov JM, Wisner KL \& Klebanoff MA. Racial and seasonal differences in 25-hydroxyvitamin D detected in maternal sera frozen for over 40 years. British Journal of Nutrition 2009101 278-284.

29 Sherman SS, Hollis BW \& Tobin JD. Vitamin D status and related parameters in a healthy population: the effects of age, sex, and season. Journal of Clinical Endocrinology and Metabolism 199071 405-413.

30 Engelsen O, Brustad M, Aksnes L \& Lund E. Daily duration of vitamin D synthesis in human skin with relation to latitude, total ozone, altitude, ground cover, aerosols and cloud thickness. Photochemistry and Photobiology 200581 1287-1290.

31 Hoffmann D, Hoffmann I \& El-Bayoumy K. The less harmful cigarette: a controversial issue. A tribute to Ernst L. Wynder. Chemical Research in Toxicology 200114 767-790.

32 Jorde R, Saleh F, Figenschau Y, Haug E \& Sundsfjord J. Serum parathyroid hormone (PTH) levels in smokers and non-smokers. The fifth Tromsø study. European Journal of Endocrinology 200515 $239-245$

33 Jorde R \& Figenschau Y. Serum TSH in smokers and non-smokers. The 5th Tromsø Study. Experimental and Clinical Endocrinology and Diabetes 2006114 343-347.

34 Vine MF. Smoking and male reproduction: a review. International Journal of Andrology 199619 323-337.

35 Sneve M \& Jorde R. Cross-sectional study on the relationship between body mass index and smoking, and longitudinal changes in body mass index in relation to change in smoking status: the Tromso Study. Scandinavian Journal of Public Health 200836 397-407.

36 Wortsman J, Matsuoka LY, Chen TC, Lu Z \& Holick MF. Decreased bioavailability of vitamin D in obesity. American Journal of Clinical Nutrition 200072 690-693.

37 Binkley N, Krueger D, Gemar D \& Drezner MK. Correlation among 25-hydroxy-vitamin D assays. Journal of Clinical Endocrinology and Metabolism 200893 1804-1808.

38 Carter GD \& Jones JC. Use of a common standard improves the performance of liquid chromatography-tandem mass spectrometry methods for serum 25-hydroxyvitamin D. Annals of Clinical Biochemistry 200946 79-81.

Received 10 April 2010

Accepted 17 May 2010 